\title{
Scientific Misconduct, Kuhnian Scientific Revolutions and Scientific Ethics.
}

\section{Author: H.Y. Lim Tung}

Correspondence to: H.Y. Lim Tung

Peptide and Protein Chemistry Research Laboratory

Nacbraht Biomedical Research Institute

3164 21st Street, Suite 117

Astoria (NYC), NY 11106

USA

Tel: 646-500-1728

E mail: hyltung2010@nacbrahtbiomedresins.net 


\begin{abstract}
:
With increased occurrences of Scientific Misconduct in the form of Scientific Misconduct, Scientific Fraud and Dishonest Scientific Report being reported in leading Scientific Journals and in the regular press, it is befitting to ask whether Kuhn's "Theory of Scientific Revolutions" foresaw the epidemic that afflicts the Scientific World and Enterprise. This analysis reflects that even though Thomas Kuhn did not deal directly with Scientific Misconduct, Scientific Fraud and Dishonest Scientific Report, his theory excludes Data fabrication, Data Falsification and Dishonest Scientific Report as part of scientific discoveries. A proposal to prevent or eradicate the commiting of Scientific Misconduct, Scientific Fraud and Dishonest Scientific Report is put forward for discussion purposes.
\end{abstract}

Key words: Scientific Misconduct, Scientific Fraud, Thomas Kuhn, Karl Popper, Scientific Ethics, 


\section{Scientific Misconduct, Scientific Fraud and Dishonest Scientific Report}

"Research Misconduct" is defined as "fabrication, falsification or plagiarism in proposing, performing or reviewing research, or in reporting research results", pursuant to the Office of Research Integrity (ORI) of the US Government's Department of Health and Human Services that oversees and regulates the activities of the US National Health Institutes with an annual budget of over 39 billion US dollars in 2019 which is no small change. There is hardly any watchdog to guard this pile of gold. It is not surprising that many have tried to take advantage of the laxity of the NIH. Recently, there has been much press coverage of Scientific Researchers being investigated, sanctioned, prosecuted and even imprisoned for committing Scientific Misconduct and Scientific Fraud [1-5]. A number of Scientific Researchers have tried unsuccessfully to sue the regular press for reporting on the occurrence of Scientific Misconduct and Scientific Fraud [6,7]. Indeed, even Politicians have taken much interest on the subject of Scientific Misconduct and Scientific Fraud, and have pressed for more draconian and severe punishments for Tricksters who commit Scientific Fraud [8-10].

Currently, the ORI does not have authority to actually investigate cases of "Research Misconduct" or Scientific Fraud or Dishonest Scientific Report. All investigations of allegations of "Research Misconduct" are forwarded to the Institutions where the alleged Scientific Misconduct, a situation that can be summarized as guarding the chickens by the fox or the sheep by the wolf. After the allegations of "Research Misconduct" have been investigated, the results of the investigation are sent to the ORI and if the ORI agrees that "Research Misconduct" has occurred, the Perpetrator of "Research Misconduct" is 
sanctioned by debarment from applying for any grants from the NIH and participating in any activities of the NIH.

\section{Scientific Misconduct and Kuhnian Scientific Revolutions}

Why are there so many cases of Scientific Misconduct, Scientific Fraud and Dishonest Scientific Report being uncovered now? According to a study of Bhumika Bhatt [11], with a total of 253 retracted Scientific Articles, the Journal of Biological Chemistry occupies the top honor (or dishonor) list of the total number of retracted Scientific Articles. Other so called Top Tier Journals, Plos One (132 retractions), Proceedings of the National Academy of Sciences over 100 retractions), Science (over 80 retractions) and Nature (over 70 retractions) are among those that have retracted the highest number of Scientific Articles. Despite being a relative new comer, Tumor Biology had almost 145 retractions. Fang et al's study [12] shows that most retraction are due to Scientific Misconduct. A more recent study by CamposVarela and Ruano-Ravina [13] confirms and extends the study of Fang et al. [ ]. Perhaps more alarming is the study by Bik et al. that suggests that as a result of inappropriate image manipulation (a form of Scientific Misconduct through Data Fabrication and Data Falsification , many Scientific Articles ought to be retracted but are not. Bik et al. investigated 20,261 that were published between 1995 to 2014 and concluded that almost 783 (3.8\%) contained images that were manipulated [14]. Further studies by Bik et al. [15] found that 50\% (6.1\%) of 960 papers published between 2009 and 2016 in Molecular and Cellular Biology contained "inappropriately duplicated images" and that $\sim 10 \%$ of these papers were retracted. 
Extrapolating from these figures, Bik et al [15] suggest that as many as 35000 papers in the literature could potentially be retracted.

Is one condemned to live with Tricksters who commit Scientific Misconduct, Scientific Fraud and Dishonest Scientific Report. Apart from the haphazard approach of the ORI, consisting mainly of allowing the Research Universities and Research Institutions to police themselves, no proposal of any concrete solutions that are based on philosophical underpinnings has been put forward. Solutions to the increase of the occurrence of Scientific Misconduct, Scientific Fraud and Dishonest Scientific Report must be grounded not only on the traditions of the Scientific Research Enterprise consisting of openness, truthfulness and reproducibility but also on the Philosophy of Science. Can one do proper Scientific Research without having read "The Theory of Scientific Revolutions" by Thomas Kuhn [16] and the book, "The Logic of Scientific Discovery" by Karl Popper [17] Thomas Kuhn's “Theory of Scientific Revolutions" rests upon the concept that there are period change of the school of thoughts that govern any scientific discipline (Paradigm Shift) through revolutions of ideas and executions. A paradigm shift occurs when it cannot explain the phenomenon observed or theorized upon anymore. Thomas Kuhn sees the progress of science as consisting of discrete revolutions of thoughts and acts termed 'paradigms". Karl Popper's idea rests upon the concept of "fasification" and "falsificationism". He views the progress of science as successive rejection of falsified theories and not of falsified statement. He envisions that "one necessarily moves from one theory by falsifying it (showing it to be wrong) to another theory that can account for the unexplained phenomenon. 
Although neither Thomas Kuhn or Karl Popper dealt directly with Scientific Misconduct and Scientific Fraud, their ideas and most importantly their writings and messages that they confer seem to certify that one cannot do Scientific Research by cheating because if it is important, every Scientific Researchers in the particular area of research will want to test or use the "paradigm" as per Thomas Kuhn or falsify the theory as per Karl Popper.

How studying the Philosophy of Science and Ethics can impact the way one does Scientific Research? Whether one agrees with Thomas Kuhn or Karl Popper (it is known that they intensely disliked each other), the work of a Scientific Researcher is constrained by the "paradigm" or "theory". To work within a "paradigm" or "theory", the Scientific Researcher must through agreed upon ideas perform experiments to generate Scientific Data that tend to support the "paradigm" or "theory". It goes without saying that the Scientific Data cannot be fabricated or falsified because the Scientific Community will not allow it and the Scientific Data will not in anyway help to solve any Scientific Problem or understand or cure any disease states. Similarly, if the Scientific Researcher wishes to venture beyond the "paradigm" or "theory", the Scientific Researcher must disprove the "paradigm" or falsify the "theory" and this can only be done with valid ideas and most importantly with experiments backed by solid Scientific Data. There is no room for trickery because resorting to trickery in the form of Data Fabrication and Data Falsification does not comply with agreed upon rules and procedures that are inherent of 
Scientific Research. It is impossible to prove or disprove a "Kuhnian Paradigm" or "Popperian Theory" via Data fabrication and Data Falsification. Feyerabed and Kuhn's concept of "incommensurabilty" [18,19] dictates that the language of Tricksters in the forms of Fabricate Data, Falsified Data and Dishonest Scientific Report will be incomprehensible to the language of Scientific Researchers who do not resort to Data Fabrication, Data Falsification and Dishonest Scientific Report. That is the main reason why Graduate Students must be exposed to the Philosophy of Science and Ethics.

\section{$\underline{\text { Scientific Ethics }}$}

None of Thomas Kuhn ideas and concepts will be worth anything if the Practitioners of Science do not follow certain traditions and rules that are ingrained in their respective disciplines. Scientific Ethics provide the boundaries that the Practitioners of Science should not cross. Talking about Scientific Ethics is a good start. However, concrete actions that apply the Principles of Scientific Ethics must be taken, At the present, Graduate Students are not taught the Principle of Scientific Ethics. Most Principal Scientific Researchers have also not been exposed to the Principles of Scientific Ethics which not just concern Scientific Misconduct in the form of Data Fabrication, Data Falsification and Dishonest Scientific Report but also other aspects including the treatment of animals in the laboratory and way clinical trials are performed. It seems to this author that applying the Principles of Scientific Ethics in concrete terms will help prevent or perhaps eradicate the occurrence of Scientific Misconduct in the form of Data Fabrication, Data Falsification and Dishonest Scientific Report. 
Scientific Research is an endeavor that consists of the search for ideas and methods to explain natural phenomena, construct practical objects, understand and find cures for disease states. As stated above, there is a way of doing Scientific Research that does not include resorting to trickery in the form of Data Fabrication, Data Falsification and Dishonest Scientific Report. Scientific Ethics is concerned with the way of doing Scientific Research ethically. Talking and discussing about Research Ethics is a good start [19-22]. However, concrete actions that apply the Principles of Scientific Ethics must be taken. At the present, Graduate Students are not taught the Principle of Scientific Ethics. Most Principal Scientific Researchers have also not been exposed to the Principles of Scientific Ethics which not just concern Scientific Misconduct in the form of Data Fabrication, Data Falsification and Dishonest Scientific Report but also other aspects, including the treatment of animals in the laboratory and the way clinical trials are performed. It is the belief of this author that applying the Principles of Scientific Ethics in concrete terms will help prevent or even eradicate the occurrence of Scientific Misconduct in the form of Data Fabrication, Data Falsification and Dishonest Scientific Report.

It is proposed that the Scientific Community at large, including the Research Universities, the Research Institutes, the Pharmaceutical Companies, the Biotechonology Companies, the Principal Investigators, the Post-Doctorals, the Students and the Government Research Agencies and Private Research Foundations that fund Scientific Research, must institute and fund an Independent Commission on the Investigation of Scientific 
Misconduct (ICISM) and an Independent Tribunal for the Ruling of Scientific Ethics Violations (ITRSEV) with the mandate to independently rule upon the following violations of Scientific Ethics and sanction the offenders of Scientific Ethics accordingly:

\section{Level One Violation (First Time Offender):}

(i) Data Fabrication.

(ii) Data Falsification.

(iii) Dishonest Scientific Report.

(iv) Theft of Ideas.

(v) Theft of Scientific Data.

(vi) Plagiarism.

(vii) Publishing Scientific Articles that contain Fabricated Data, Falsified Data, Dishonest Scientific Reporting, Stolen Ideas, Stolen Scientific Data and Plagiarized material.

(viii) No Documented Recording of Experiments Performed.

(ix) No Documented Recording of Analysis of Results of Experiments Performed.

(x) No Documented Recording of Calculations Performed.

$\underline{\text { Level Two Violation (Second Time Offender) }}$

(i) Data Fabrication.

(ii) Data Falsification. 
(ii) Dishonest Scientific Report.

(iii) Theft of Ideas.

(iv) Theft of Scientific Data.

(v) Plagiarism.

(vi) Publishing Scientific Articles that contain Fabricated Data, Falsified Data, Dishonest Scientific Reporting, Stolen Ideas, Stolen Scientific Data and Plagiarized material.

(vii) No Documented Recording of Experiments Performed.

(viii) No Documented Recording of Analysis of Results of Experiments Performed.

(ix) No Documented Recording of Calculations Performed.

\section{Level Three Violation (Third Time Offender)}

(i) Data Fabrication.

(ii) Data Falsification.

(iii) Dishonest Scientific Report.

(iv) Theft of Ideas.

(v) Theft of Scientific Data.

(vi) Plagiarism.

(vii) Publishing Scientific Articles that contain Fabricated Data, Falsified Data, Dishonest Scientific Reporting, Stolen Ideas, Stolen Scientific Data and Plagiarized material.

(viii) No Documented Recording of Experiments Performed. 
(ix) No Documented Recording of Analysis of Results of Experiments Performed.

(x) No Documented Recording of Calculations Performed.

\section{$\underline{\text { Level Four Violations }}$}

(i) Unethical treatment of animals.

(ii) Unethical treatment and abuse of animals.

(iii) Publishing Scientific Articles in which Animal Subjects are reported but no Institutional Permits exist.

(iv) Continuation of Experiments involving Animal Subjects that have no benefit and are in fact harmful.

\section{$\underline{\text { Level Five Violations }}$}

(i) Unethical Treatment of Human Subjects.

(ii) Unethical Treatment and abuse of Human Subjects resulting in bodily and mental harm.

(iii) Using Human Subjects without their consent.

(iv) Treating Human Subjects without their consent.

(v) Publishing Scientific Articles of non-existent Human Subjects (i.e fabricated data from fictitious Human Subjects)

(vi) Publishing Scientific Articles in which Human Subjects are reported without their consent. 
(vii) Publishing Scientific Articles in which Human Subjects are reported but no Institutional Permits exist.

(viii) Continuation of Experiments involving Human Subjects and Clinical Trials that have no benefits and are in fact harmful.

(ix) Non-Treatment of Human Subjects when the Clinical Trials show Drugs or Devices under investigation are effective.

Level Six Violations:

(i) Unethical Treatment and abuse of Human subjects resulting in death.

(ii) Scientific Fraud.

If an individual has been found guilty of violating the Codes of Scientific Ethics, that individual must be sanctioned depending on the severity of the violation.

Level One Violations is to be sanctioned by Debarment for three years from obtaining any Research Grants from Government Funding Agencies and Private Research Foundations.

Level Two Violations is to be sanctioned by Debarment for five years from obtaining any Research Grants from Government Funding Agencies and Private Research Foundations. 
Level Three Violations is to be sanctioned by Debarment for ten years from obtaining any Research Grants from Government Funding Agencies and Private Research Foundations.

Level Four Violations (involving abuse and mistreatment of Animal Subjects) is to be sanctioned by Debarment for fifteen years from obtaining any Research Grants from Government Funding Agencies and Private Research Foundations.

Level Five Violations (involving physical and mental harm of Human Subjects) is to be sanctioned by Debarment for twenty years from obtaining any Research Grants from Government Funding Agencies and Private Research Foundations.

Level Six Violations (involving death of Human Subjects or Scientific Fraud) is to be sanctioned by Debarment for twenty five years from obtaining any Research Grants from Government Funding Agencies and Private Research Foundations and Recommending Criminal Prosecution.

The annual budget for the NIH is approximately 39 billion US Dollars. Any responsible person or government would want to make sure that the money is well spent and not being wasted. If the conservative estimate that $1 \%$ of all NIH funded Research Grants are bogus, it means that at least 390 million US Dollars is being wasted in 2019 alone. The equivalent of $0.2 \%$ of the annual NIH budget (i.e $\sim 70$ million US Dollars) can be devoted to an Independent Commission for the Investigation of Scientific Misconduct 
(ICISM) and the Independant Tribunal for the Ruling of Scientific Ethics Violations (ITRSEV). The money can come from voluntary contributions from the Research Universities and Institutions or the NIH could decide that all grants will be taxed at the level of $0.2 \%$ and paid to the Independant Commission for the Investigation of Scientific Misconduct (ICISM) When one considers that at least $1 \%$ of the total NIH is wasted on bogus research, the approximately 70 million US Dollars will be well spent. The Scientific Researchers, the Research Universities and Institutions, the Governmental Granting Agencies like the NIH, NSF, Department of Defense must voluntarily seek to establish the Independant Commission for the Investigation of Scientific Misconduct (ICISM) and the Independent Tribunal for the Ruling of Scientific Violations (ITRSEV) for the following reasons:

(i) It will prove to the US Government, the US Congress and the People who foot the bills that the Scientific Community at large is serious at exposing and combating Scientific Misconduct, Scientific Fraud and Dishonest Scientific Report .

(i) It will avoid the farcical inquisition witnessed in the Matter of US Congress v. Teresa Iminashi-Kari and David Baltimore and in the Matter of the ORI v. and Teresa IminashiKari and David Baltimore.

(ii) It will avoid the partial treatment of Respondents as seen in the Matter of the ORI v. Teresa Iminashi-Kari and David Baltimore and in the Matter of U.S.A. v. Dong-Pyou Han.

(iii) It will prevent Outside Vigilantes like Senators Grassley and Dingall from interfering and dictating how Scientific Research must proceed and how it must be run. 
(iv) It will prevent self proclaimed Fraud Busters like Stewart and Nader from interfering in legitimate investigation of Scientific Misconduct, Scientific Fraud and Dishonest Scientific Report.

(v) It will show that the investigation, determination and ruling of Scientific Misconduct, Scientific Fraud and Dishonest Scientific Report will be fair, procedural and impartial.

(vi) It will provide Due Process of the Law to both the Complainants and the Respondents.

(vii) It will provide complete transparency with respect to the investigation, ruling and sanctioning of Scientific Misconduct, Scientific Fraud and Dishonest Scientific Report.

(viii) It will prevent and dissuade would be perpetrators from committing Scientific Misconduct, Scientific Fraud and Dishonest Scientific Report.

The Scientific Research Communities in U.S.A, Canada, Europe, and elsewhere must wake up or they will be forced to act in ways that contravene the tradition of openness, fairness and impartiality that are ingrained in the Scientific Research Enterprise by the politicians and other interested groups.

\section{Acknowledgments:}

The work was supported by Nacbraht Biomedical Research Institute. The author has no conflict of interest with respect to this work. 


\section{References:}

1. Tung, H.Y.L. (2019) In the Matter of Scientific Misconduct, $1^{\text {st }}$ ed., Astoria (NYC), N.Y., Cactoa Scientific Publishers, Inc.

2. Sox, H.C. and Rennie, D. (2006) Annals of Internal Medicine. Vol 144, pp609613.

3. Tung, H.Y.L., (2019) in In the Matter of Scientific Misconduct and Fraud, 1st ed. Astoria (NYC), N.Y., Cactoa Scientific Publishers, Inc., pp73-76. In the Matter of U.S.A v. Dong-Pyou Han.

4. White, P.F., Fanzca, R., Carl, E. and Steven,L. (2011) Anesthetic \& Analgesia. Vol 112, pp512-515.

5. U.S.A. v. Craig Grimes (2014) United States Court of Appeals Forthe Third Circuit, No. 12-4523.

6. Carlo Croce v. The New York Times et al. (2019) United States Court of Appeals for the Six Circuit, No. 18-14158.

7. Fazhul Sarkar v. John Doe and Jane Doe and PubPeer Foundation (2016) Michigan Court of Appeal, No. 326607, WL No. 14-01399-CZ

8. Nutt, A.E. (2016) in The Washington Post, Issue of April 1, 2016.

This scientist nearly went to jail for making up data.

9. Philip, A. (2015) in The Washington Post, Issue of July 1, 2015.

Researcher who spiked rabbit blood to fake HIV vaccine results slapped with rare prison sentence.

10. https//oro.hhs.gov. 
11. Bhatt, B. (2019) in Towards Data Science, Issue of March 23, 2019. [https://towardsdatascience.com.]

On Retractions in Biomedical Literature.

12. Fang, F.C., Steen, R.G. and Casadevall, A. (2012) Proc. Natl. Acad. Sci. Vol 109, pp17028-17033.

13. Bik, E.M., Fang, F.C., Kulias, A.L., Davis, R.J. and Casadevall, A. (2016) mBio, Vol 7, e00809-16

The Prevalence of Inappropriate Image Duplication in Biomedical Research Publication

14. Bik, E.M., Fang, F.C., Kulias, A.L., Davis, R.J. and Casadevall, A. (2018) Mol. Cell. Biol. Vol 38, pp309-318.

Analysis and Correction of Inappropriate Image Duplication: the Molecular and Cellular Biology Experience.

15. Kuhn, T.S. (1996) The Structure of Scientific Revolutions, 3rd ed. Chicago, IL: University of Chicago Press.

16. Popper, K.R. (1968) The Logic of Scientific Discovery, 6th ed. New York: Harper \& Row.

17. Feyerabed, P.K. (1970) Problem of Empiricism, Cambridge, UK: Cambridge University Press.

18. Kuhn, T.S. (2000) The Road Since Structure, Chicago, Il: University of Chicago Press.

19. Sharma, O.P. (2015) Indian J. Microbiol. Vol 55, pp341-344. 
Ethics in Science.

20. Korenman, S.G., Berk, R., Winger, N.S. and Lew, V. (1998) JAMA. Vol 279, pp41-47.

Evaluation of the research norms of scientists and administrators responsible for academic research intergrity.

21. Conzin-Frankel, J. (2013) Science. Vol 339, pp386-389.

Shaking up Science.

22. Weinbaum, C., Landree, E., Blumenthal. M.S., Puquano, T. and Gutierrez, C.I. (2019) An Examination of Ethics Principles and Emergin Topics. Chicago, IL: Rand Corporation [https://www.rand.org/pubs/research_reports IRR2912.html] 